\title{
CRÓNICA PARLAMENTARIA DEL SENADO (II)
}

M." VICTORIA GARCIAA-ATANCE

Profesora Titular de Derecho Constitucional 


\section{SUMARIO}

IV. Actividad finanCiera.-IV-A. Materia presupuestaria.- IV-B. Materia tributaria.-V. ACTIVIDAD DE CONTROL.-V-A. Mociones.$V$ - B. Comisiones de investigación.- V-C. Interpelaciones. $-V$ D. Preguntas.-VI. Relaciones del SENAdo con otros óRganos E INSTITUCIONES PÚBliCAS.-VI-A. Tribunal Constitucional.-VI-B. Poder Judicial.-VI-C. Tribunal de Cuentas.-VI-D. Defensor del Pueblo.-VII. Actividad de la Cámara en Relación con las CC.AA. 
Revista de Derecho Político, núm. 41, 1996, pp. 365-377

\title{
CRÓNICA PARLAMENTARIA DEL SENADO (II) (*)
}

\author{
POR \\ M. VICTORIA GARCÍA-ATANCE \\ Profesora Titular de Derecho Constitucional
}

\section{ACTIVIDAD FINANCIERA}

\section{IV-A. Materia presupuestaria}

- Proyecto de ley de Presupuestos Generales del Estado para 1990.

- Proyecto de ley sobre medidas en materia presupuestaria, financiera y tributaria.

- Proyecto de ley sobre concesión de un crédito extraordinario para completar el pago a la Compañía Transmediterránea, S. A.

- Proyecto de ley sobre concesión de un crédito extraordinario a Ferrocarriles de la Generalidad de Cataluña.

- Proyecto de ley de Presupuestos Generales del Estado para 1991.

- Proyecto de ley por el que se aprueba el convenio económico entre el Estado y la C. A. Foral de Navarra.

- Proyecto de ley de Presupuestos Generales del Estado para 1992.

- Proyecto de ley de Presupuestos Generales del Estado para 1993.

(*) Segunda parte. 


\section{IV-B. Materia tributaria}

- Proyecto de ley por el que se establecen en la Seguridad Social prestaciones no contributivas.

- Proyecto de ley por el que se modifica parcialmente la Ley $42 / 1983$, de 28 de diciembre, reguladora de la cesión de tributos a la C. A. de Madrid.

- Proyecto de ley de régimen fiscal de las cooperativas.

- Proyecto de ley de beneficios fiscales relativos a Madrid, capital europea de la cultura.

- Proyecto de ley de modificación de los aspectos fiscales del régimen económico fiscal de Canarias.

- Proyecto de ley de incentivos fiscales aplicables al proyecto Cartuja 1993.

- Proyecto de ley de Impuesto sobre el Valor Añadido.

- Proyecto de ley sobre liquidación definitiva de la participación de las Corporaciones Locales en los tributos del Estado, del ejercicio 1990.

- Proyecto de ley de adaptación del convenio económico entre el Estado y Navarra a la Ley del IVA y la Ley de Impuestos Especiales.

\section{ACTIVIDAD DE CONTROL}

Procederemos en el presente punto, dada la ingente casuística de las distintas manifestaciones en que se activa la función de control de la Cámara, a presentar esta actividad en cuadros que permiten reflejarla de una manera más gráfica, aunque no tan pormenorizada como lo sería la relación de todas y cada una de dichas manifestaciones, que aquí, por razones obvias, no puede recogerse. 
CRÓNICA PARLAMENTARIA DEL SENADO (II)

Resumen de actos de control (noviembre 89-abril 93)

\begin{tabular}{lccc}
\hline & Presentadas & Tramitadas & \multicolumn{2}{c}{ Caducadas } \\
\hline Preguntas escritas & 11.917 & 11.048 & 590 \\
\hline Preguntas orales en Pleno & 954 & 767 & 2 \\
\hline Preguntas orales en Comisión & 176 & 171 & 4 \\
\hline Interpelaciones & 441 & 155 & 2 \\
\hline Mociones & 205 & 146 & 14 \\
\hline
\end{tabular}


Resumen de actos de control por períodos de sesiones

\begin{tabular}{|c|c|c|c|c|c|c|}
\hline & \multicolumn{3}{|c|}{ Noviembre-diciembre 89} & \multicolumn{3}{|c|}{ Enero-junio 90} \\
\hline & Presentadas & Tramitadas & Caducadas & Presentadas & Tramitadas & Caducadas \\
\hline Preguntas escritas & 221 & 221 & - & 2.045 & 2.005 & 16 \\
\hline Preguntas orales en Pleno & 22 & 14 & - & 205 & 138 & - \\
\hline Preguntas orales en Comisión & 1 & - & 1 & 5 & 5 & - \\
\hline Interpelaciones & 6 & 3 & - & 71 & 30 & - \\
\hline Mociones & 12 & 5 & - & 38 & 29 & - \\
\hline
\end{tabular}

\begin{tabular}{|c|c|c|c|c|c|c|}
\hline & \multicolumn{3}{|c|}{ julio-diciembre 90} & \multicolumn{3}{|c|}{ Enero-junio 91} \\
\hline & Presentadas & Tramitadas & Caducadas & Presentadas & Tramitadas & Caducadas \\
\hline Preguntas escritas & 1.171 & 1.154 & 3 & 1.731 & 1.704 & 15 \\
\hline Preguntas orales en Pleno & 22 & 14 & - & 145 & 121 & - \\
\hline Preguntas orales en Comisión & - & - & - & 1 & 1 & - \\
\hline Interpelaciones & 51 & 20 & - & 60 & 23 & - \\
\hline Mociones & 34 & 26 & 1 & 22 & 17 & - \\
\hline
\end{tabular}


Resumen de actos de control por períodos de sesiones (cont.)

\begin{tabular}{lcccccc}
\hline & \multicolumn{3}{c}{ Julio-diciembre 91 } & \multicolumn{2}{c}{ Enero-junio 92 } \\
\cline { 2 - 7 } & Presentadas & Tramitadas & Caducadas & Presentadas & Tramitadas & Caducadas \\
\hline Preguntas escritas & 1.899 & 1.730 & 5 & 2.024 & 1.971 & 7 \\
\hline Preguntas orales en Pleno & 111 & 96 & - & 166 & 141 & - \\
\hline Preguntas orales en Comisión & 1 & - & 1 & 144 & 144 & - \\
\hline Interpelaciones & 76 & 21 & - & 100 & 25 & - \\
\hline Mociones & 36 & 23 & 3 & 24 & 19 & 1 \\
\hline
\end{tabular}

\begin{tabular}{|c|c|c|c|c|c|c|}
\hline & \multicolumn{3}{|c|}{ julio-diciembre 92} & \multicolumn{3}{|c|}{ Enero-abril 93} \\
\hline Preguntas escritas & 1.379 & 1.357 & 12 & 1.447 & 906 & 532 \\
\hline Preguntas orales en Pleno & 115 & 93 & - & 77 & 70 & 2 \\
\hline Preguntas orales en Comisión & 21 & 21 & - & 3 & - & 2 \\
\hline
\end{tabular}


Resumen de actos de control por Grupos Parlamentarios

\begin{tabular}{|c|c|c|c|c|c|}
\hline Autores & $\begin{array}{l}\text { Preguntas } \\
\text { escritas }\end{array}$ & $\begin{array}{c}\text { Preguntas } \\
\text { orales en Pleno }\end{array}$ & $\begin{array}{c}\text { Preguntas } \\
\text { orales en Comisión }\end{array}$ & Interpelaciones & Mociones \\
\hline Socialista & 546 & 333 & 1 & - & $13^{4-2}$ \\
\hline $\begin{array}{l}\text { Catalán en el Senado } \\
\text { de Convergéncia i Uniò }\end{array}$ & 137 & 57 & - & 38 & $14^{\prime}$ \\
\hline Centro Democrático y Social & 13 & 62 & 4 & 59 & $20^{1}$ \\
\hline Mixto & 613 & 132 & 1 & 142 & $41^{1-2}$ \\
\hline
\end{tabular}

Una moción fue presentada conjuntamente por todos los Grupos Parlamentarios.

2 Una moción fue presentada conjuntamente por los Grupos Parlamentarios Socialista, Popular y Mixto. 


\section{Preguntas escritas}

\begin{tabular}{|c|c|c|c|c|c|c|c|}
\hline Periodo & Presentadas & No admitidas & Retiradas & Convertidas & Contestadas & Decaídas & Caducadas \\
\hline Nov.-Dic. 89 & 221 & - & - & - & 221 & - & - \\
\hline Ene.-Jun. 90 & 2.045 & 10 & 14 & - & 2.005 & - & 16 \\
\hline Jul.-Dic. 90 & 1.171 & 6 & 7 & 1 & 1.154 & - & 3 \\
\hline Ene.-Jun. 91 & 1.731 & 4 & 8 & - & 1.704 & - & 15 \\
\hline Jul.-Dic. 91 & 1.899 & 12 & 7 & 145 & 1.730 & - & 5 \\
\hline Ene.-Jun. 92 & 2.024 & 6 & 19 & 20 & 1.971 & 1 & 7 \\
\hline Jul.-Dic. 92 & 1.379 & 3 & 6 & 1 & 1.357 & - & 12 \\
\hline Ene.-Abr. 93 & 1.447 & 9 & - & - & 906 & - & 532 \\
\hline TOTAL & 11.917 & 50 & 61 & 167 & 11.048 & 1 & 590 \\
\hline
\end{tabular}




\section{RELACIONES CON OTROS ÓRGANOS E INSTITUCIONES PÚBLICAS}

\section{VI-A. Tribunal Constitucional}

\section{Elección de Magistrados}

El Pleno del Senado, en sesión de 30 de junio de 1992, eligió a D. José Gabaldón López como Magistrado del Tribunal Constitucional, para cubrir la vacante producida por la renuncia de $D$. José Luis de los Mozos.

\section{Recursos de inconstitucionalidad}

- N.190/91, planteado por D. Luis Fernández Fernández, sobre derechos de información de los representantes de los trabajadores en materia de contratación.

- N. 746/91, presentado por el Senador D. Luis Fernández Fernández, contra determinados preceptos de la Ley de la Asamblea de Extremadura sobre caza.

- N.2709/92, presentado por Ruiz-Gallardón, sobre la Ley de policía del País Vasco.

- N.⒐93/93, presentado por Ruiz-Gallardón, sobre la Ley de impuestos especiales.

Recursos de amparo que atañen directamente a Senadores

- Interpuesto por D. Joaquín Ferrer i Roca contra los acuerdos de la Mesa del Senado, por no admitir a trámite una moción relativa al uso de lenguas oficiales. STC 205/1990 estimativa.

- Interpuesto por D. José Luis Álvarez Esperanza contra la decisión del Presidente del Senado que rechazó la fórmula de juramento utilizada por ciertos Senadores. STC 74/1991 estimativa.

- Interpuesto por D. Juan Hormaechea Cazón contra el acuerdo del Pleno del Senado de denegación de la autorización de procesamiento del Senador González Bedoya. STC de 27 de noviembre de 1992, estimativa. 
Declaraciones del TC que afectan al Senado

- EI TC dictó, en fecha 15 de noviembre de 1989, Auto sobre la consulta del Senador Ortí Bordás sobre la garantía del pleno derecho a interponer recursos de inconstitucionalidad en el período de tiempo que están disueltas las Cámaras.

- Requerido para pronunciarse sobre la posible contradicción entre el art. 13.2 de la CE y el art. 8 B, apartado I, del Tratado constitutivo de la Comunidad Europea.

\section{VI-B. Poder Judicial}

En relación con el Consejo General del Poder Judicial, la Cámara, en sesión celebrada el 6 de noviembre de 1990, procedió a la elección de determinadas personas para ser propuestas al Rey para su nombramiento como Vocales del Consejo General del Poder Judicial.

Asimismo, en relación con esta institución, se presentaron en la Cámara cuatro memorias sobre el estado, funcionamiento y actividades del Consejo y de los Juzgados y Tribunales de Justicia, correspondientes a los ejercicios 1988, 89, 90 y 91; enviándose a su vez las comunicaciones siguientes: el acuerdo del Pleno del Consejo del nombramiento de su Vicepresidente; el acuerdo del cese de D. Eligio Hernández como Vocal del Consejo, al tomar posesión del cargo de Fiscal General del Estado, y el acuerdo del pleno del Consejo de fecha 6 de octubre de 1992 en que manifiesta a la Cámara su preocupación por no haber sido sometido al preceptivo informe del Consejo el Anteproyecto de Ley de las Administraciones Públicas y del Procedimiento Administrativo Común.

\section{VI-C. Tribunal de Cuentas}

El Pleno el Senado, en sesión celebrada el 19 de diciembre de 1991, procedió a la designación de determinados Consejeros de Cuentas del Tribunal.

La Comisión Mixta para las Relaciones con el Tribunal de Cuentas ha tramitado la Cuenta General del Estado correspondiente a los ejercicios: 
- 1985. "B.O.C.G." Cortes Generales, serie I, n. 74, de 26 de mayo 1990; Diario de Sesiones, Pleno de 26 de mayo de 1990.

- 1986. "B.O.C.G." Cortes Generales, serie I, n. 140, de 26 de noviembre de 1990; Diario de Sesiones, Pleno de 21 de noviembre de 1990.

- 1987. «B.O.C.G." Cortes Generales, serie A, n. 18, de 25 de septiembre de 1991; Diario de Sesiones, Pleno de 18 de septiembre de 1991.

- 1985. "B.O.C.G." Cortes Generales, serie A, n.o 43, de 19 de junio de 1992; Diario de Sesiones, Pleno de 10 de junio de 1992.

El informe anual del Tribunal de Cuentas del ejercicio 1989 y la Declaración Definitiva de la Cuenta General del Estado 1989 fueron remitidos a la Cámara el 18 de febrero de 1993, hallándose en tramitación al finalizar la Legislatura.

La Comisión Mixta para las Relaciones con el Tribunal de Cuentas se ha ocupado de un total de 14 informes, siete de ellos tenían su origen en la III Legislatura, siendo de diversa índole, como: ingresos y gastos de los Partidos Políticos en las elecciones europeas, autonómicas y locales; fiscalización de la contabilidad de distintos Ayuntamientos; del Ente Público Radiotelevisión Española, y otras materias.

\section{VI-D. Defensor del Pueblo}

En lo referente a miembros de la institución, la Comisión de la Cámara encargada de las Relaciones con el Defensor del Pueblo, otorga su conformidad al nombramiento del Adjunto Segundo del Defensor del Pueblo, así como recibe en fecha 16 de marzo de 1993 el comunicado en que se declaraba vacante el cargo de Defensor del Pueblo por expiración del mandato de D. Álvaro Gil Robles.

Se han presentado los informes anuales correspondientes a los siguientes ejercicios:

- 1989. "B.O.C.G." Senado, Serie I, n. ${ }^{\circ}$ 62, de 9 de mayo de 1990; Diario de Sesiones, Pleno n.․ 21, de 6 de junio de 1990.

- 1990. "B.O.C.G." Senado, Serie I, n.o 202, de 3 de mayo de 1991; Diario de Sesiones, Pleno n. 75 , de 19 de junio de 1991. 
- 1991. "B.O.C.G." Cortes Generales, Serie A, n. -37, de 25 de abril de 1992; Diario de Sesiones, Pleno n.. 127, de 16 de septiembre de 1992.

El informe del ejercicio de 1992 fue publicado en el "B.O.C.G." Cortes Generales A-51, de 24 de febrero de 1993, no habiéndose terminado su tramitación al finalizar la Legislatura.

Además, el Defensor del Pueblo remitió a la Cámara otros dos estudios sobre la situación de los menores en centros asistenciales.

\section{ACTIVIDAD DE LA CÁMARA EN RELACIÓN CON LAS CC.AA.}

En relación con las Comunidades Autónomas, merece señalarse el Debate sobre el Estado de las Autonomías, celebrado los días 16 y 17 de marzo de 1993, "B.O.C.G.", Serie I, n. .225 , de 12 de marzo de 1993, Diario de Sesiones núms. 154 y 155.

Mociones presentadas, aprobadas y rechazadas, "B.O.C.G.", Serie I, n. 9432 , de 24 de marzo de 1993.

Asimismo cabe reseñarse un amplio número de comparecencias de autoridades autonómicas procedentes de diversas Comisiones autonómicas: Comisión de Agricultura, Comisión de Autonomías, Comisión Defensor del Pueblo, Comisión Especial de Seguridad Vial, Comisión Mixta de la Mujer, Comisión de la Juventud, etc.

De igual manera, la Cámara fue receptora de diversas comunicaciones e informes de procedencia autonómica, interviniendo también en distintos actos en relación con Senadores de designación autonómica. 